\title{
Schumann resonance frequency variations observed in magnetotelluric data recorded from Garhwal Himalayan region India
}

\author{
R. Chand ${ }^{1}$, M. Israil ${ }^{1}$, and J. Rai ${ }^{2}$ \\ ${ }^{1}$ Department of Earth Sciences, Indian Institute of Technology, Roorkee 247 667, India \\ ${ }^{2}$ Department of Physics, Indian Institute of Technology, Roorkee 247 667, India
}

Received: 12 November 2008 - Revised: 17 August 2009 - Accepted: 21 August 2009 - Published: 23 September 2009

\begin{abstract}
Schumann resonance (SR) frequency variation has been studied using Magnetotelluric (MT) data recorded in one of the world's toughest and generally inaccessible Himalayan terrain for the first time in the author's knowledge. The magnetotelluric data, in the form of orthogonal time varying electric and magnetic field components $\left(E_{x}, E_{y}, B_{x}\right.$ and $B_{y}$ ), recorded during 10 March-23 May 2006, in the Himalayan region, India, at elevations between $1228-2747 \mathrm{~m}$ above mean sea level (amsl), were used to study the SR frequency variation. Electromagnetic field components, in the form of time series, were recorded at $64 \mathrm{~Hz}$ sampling frequency at a site located away from the cultural noise. Spectral analysis of time series data, at a frequency resolution of $0.03 \mathrm{~Hz}$, has been performed using Fast Fourier Transform (FFT) algorithm. Spectral stabilization in three Schumann resonance modes is achieved by averaging the power spectral magnitude of 32 data segments, each with 2048 sample data. Amplitude variation in the Schumann resonance frequency associated with day-night, sunrise and terminator effect was observed. Average diurnal variation in the first three Schumann resonance frequencies associated with magnetic field components is presented. The maximum frequency variation of about $0.3,0.4$ and $0.7 \mathrm{~Hz}$ was observed in the first, second and third mode, respectively. The frequency variations observed in electric and magnetic field components also show phase shift and varying attenuation. The SR frequency variation has been used to define the ionospheric electron density variation in the Himalayan region, India.
\end{abstract}

Keywords. Ionosphere (Electric fields and currents) - Meteorology and atmospheric dynamics (Lightning) - Radio science (Electromagnetic noise and interference)

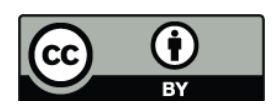

Correspondence to: $\mathrm{R}$. Chand (rkdphdes@gmail.com)

\section{Introduction}

Schumann (1952) has predicted an extremely low frequency (ELF) resonance in the earth-ionospheric waveguide. The resonance occurs between the electromagnetic wave, generated by lightning and thunderstorm, traveling along ground surface and returning to the starting point, with a phase difference of $2 \pi n$ ( $n=$ integer number). Assuming the perfectly conducting earth and ionospheric boundaries, different modes of resonance frequencies can be derived from the following relation (Schumann, 1952),

$f_{n} \equiv \frac{\omega_{n}}{2 \pi} \approx \frac{c}{2 \pi R_{E}} \sqrt{n(n+1)}=10.6 \sqrt{\frac{n(n+1)}{2}} \mathrm{~Hz}$,

where $n$ is an integer, $c$ is the velocity of light and $R_{E}$ is the radius of earth. According to Eq. (1), the first five resonance frequencies are 10.6, 18.4, 26.0, 35.5 and $41.1 \mathrm{~Hz}$. In reality, the ionosphere is not a perfectly conducting medium and energy losses due to its finite conductivity reduce the resonance frequencies to 7.8, 14.1, 20.3, 26.3 and $32.5 \mathrm{~Hz}$ (Madden and Thomson, 1965). Characteristics of Schumann resonance frequencies depend on the characteristics of their source, location of the observation point with respect to the source, and ionospheric electron density/conductivity behaviour. Thus, for a local region, assuming the average constant source distribution, Schumann resonance frequency variations can be used to determine the average conductivity profile of the ionosphere (Tran and Polk, 1979a, b). Different attenuation characteristics and frequency shifts were observed in $\mathrm{N}-$ $\mathrm{S}\left(B_{x}\right)$ and E-W $\left(B_{y}\right)$ magnetic field components (Sentman, 1987, 1989). It has been well established that the resonance frequencies contain information about space time distribution of lightning strokes around the globe. Diurnal variation in SR frequencies depends on the point of observation, which may also vary in different field components (Bliokh et al., 1980; Nickolaenko, 1997; Roldugin et al., 2004a).

Published by Copernicus Publications on behalf of the European Geosciences Union. 
Theoretically, SR frequencies can be estimated as eigenvalues by solving the wave equations using a spherically symmetric ionosphere. Steady state model for fixed ionospheric conductivity generate constant resonance frequency for each mode. By incorporating different realistic ionospheric electrical conductivity models, characteristics of resonance frequencies can be estimated (Tran and Polk, 1979a, b; Sentman, 1983).

The vertical electric field and horizontal magnetic field components show the diurnal variation in the Schumann resonance intensities (Sentman and Fraser, 1991; Märcz et al., 1997). The intensities of Schumann resonances reflect global thunderstorm activity, which excite transverse magnetic normal modes of earth ionosphere cavity (Balser and Wagner, 1962; Pierce, 1963; Sentman, 1996; Nickolaenko and Hayakawa, 2002). Penetration of electric and magnetic field components of the Schumann resonances into the ionosphere was numerically investigated by Grimalsky et al. (2005) for possible daytime and nighttime variation of conductivity in the ionospheric D- and E-layers. It was shown that the penetration height for magnetic field components is $2-3$ times greater than that for the electric field components. SR intensity and global thunderstorm activity are minimum at nighttime or early dawn and maximum in the afternoon hours (Märcz et al., 1997).

Sao et al. (1973) concluded, experimentally, that the dayto-day variation of the resonance frequency coincides with the variation of the lower ionospheric conductivity. The amplitude of Schumann resonances shows daily variability due to the polarization of the electromagnetic field radiated by lightning strokes (Füllekrug, 1995). This daily variability depends on local time. The changes in SR frequencies are sensitive to a general increase/decrease of conductivity within the outer layer (Sátori et al., 2005). It has been found, experimentally, that the variations in the N-S and E-W magnetic components occur in antiphase for the first Schumann resonance frequency (Roldugin et al., 2004a). Sátori (1996) studied that the average daily frequency patterns are different for the three modes. The frequencies in the different magnetic and electric field components are not the same. Schumann resonance frequencies determined separately for $\mathrm{N}-\mathrm{S}$ and E-W magnetic component differ by $0.5-1.8 \mathrm{~Hz}$ (Sentman, 1987, 1989). The variation in first and second mode Schumann resonance frequency occurred during the intense solar $\mathrm{X}$-ray burst by $\sim 0.2 \mathrm{~Hz}$ and $0.3 \mathrm{~Hz}$, respectively (Roldugin et al., 2004b). Hayakawa et al. (2008) showed the short term spectral modification associated with the Moshiri (Japan) earthquake, in the Schumann resonance frequency band of $2.5-40 \mathrm{~Hz}$.

The study of the Schumann resonance frequency variation has become an important tool for ionospheric characterization in terms of electron density variations and monitoring a sudden disturbance in the ionosphere during solar proton events (Roldugin et al., 2001, 2003). The precise measurements of the resonance frequencies, with high spectral reso- lution, were carried from the audiomagnetotelluric and magnetotelluric data (Beamish and Tzanis, 1986; Melnikov et al., 2004; Tulunay et al., 2008) to monitor sudden ionospheric disturbances.

In the present paper, we have carried out a spectral analysis of magnetotelluric data, recorded from the Garhwal Himalayan region, India, during 10 March-23 May 2006 to study diurnal variation in Schumann resonance frequency with a special focus on the study of day-night, morningsunrise and solar-terminator effects in the region. The SR frequency variations are also used to determine ionospheric electron density distribution assuming constant source distribution in the Indian Garhwal Himalayan region.

\section{Magnetotelluric data recording and analysis}

Magnetotelluric (MT) raw data recorded in the form of time varying orthogonal horizontal components of electric and magnetic field in the Garhwal Himalayan region, India, in a frequency range from 0.001 to $1000 \mathrm{~Hz}$, were used to determine the electrical structure of Garhwal Himalayan crust (Israil et al., 2008). To cover the desired frequency range, the data were recorded in various bands, identified by their sampling frequency. For the present study, the data recorded at 8 stations during 10 March-23 May 2006, in the Garhwal Himalayan region, were used. The GPS locations of these stations are given in Table 1. These stations were located away from cultural noise. A 24 bits Metronix MT system, which has a high dynamic range and is sensitive to measuring the field adequately with high precision, was used. A brief description of the magnetotelluric data recording system and sensors used in the present investigation are discussed below.

\section{Description of MT system and sensors}

The horizontal electric field components $\left(E_{x}\right.$ and $\left.E_{y}\right)$ were derived by measuring the voltage drop between pairs of nonpolarisable electrodes deployed in the ground. These pairs of electrodes were configured orthogonal to each other, with one pair of electrodes oriented in the magnetic north-south $(\mathrm{N}-\mathrm{S})$, measuring the $E_{x}$ component, and the other in the magnetic east-west (E-W) direction, measuring the $E_{y}$ component. The typical separation between the electrodes was kept between 60 to $90 \mathrm{~m}$. Non-polarisable lead/lead chloride electrodes (EFP06) were used to avoid distortion in the recorded signal. In order to have an optimum common mode rejection ratio of disturbing radio transmitters, the data logger (ADU06), the control and storage unit, was located in the center of the electric field dipoles.

The induction coil magnetometer (MFS06) was used to measure the horizontal orthogonal time varying magnetic field components $\left(B_{x}\right.$ and $B_{y}$ ). The induction coil magnetometer consists of a loop of copper wire wound into a high permeability core and sealed within a shock-resistant casing. 
Table 1. GPS location of stations, at which data were recorded from the Garhwal Himalayan region of India along with the duration of record, at each station.

\begin{tabular}{|c|c|c|c|c|c|}
\hline Station no. & Latitude & Longitude & $\begin{array}{l}\text { Elevation } \\
\quad(\mathrm{m})\end{array}$ & $\begin{array}{l}\text { Start date } \\
\text { \& time }\end{array}$ & $\begin{array}{l}\text { Stop date } \\
\text { \& time }\end{array}$ \\
\hline 1 & $30: 45: 2.30$ & $78: 26: 28.00$ & 1493 & $\begin{array}{c}10 \text { March } 2006 \& \text { } \\
\text { 2:19 p.m. }\end{array}$ & $\begin{array}{c}13 \text { March } 2006 \& \text { 9: } \\
\text { 9:00 a.m. }\end{array}$ \\
\hline 2 & $30: 44: 18.65$ & $78: 29: 53.58$ & 1228 & $\begin{array}{l}11 \text { March } 2006 \& \text { } \\
\text { 2:26 p.m. }\end{array}$ & $\begin{array}{c}14 \text { March } 2006 \& \text { } \\
\text { 4:30 p.m. }\end{array}$ \\
\hline 3 & $30: 49: 9.62$ & $78: 36: 37.13$ & 1895 & $\begin{array}{c}14 \text { March } 2006 \& \\
11: 36 \text { a.m. }\end{array}$ & $\begin{array}{c}17 \text { March } 2006 \& \text { } \\
10: 00 \text { a.m. }\end{array}$ \\
\hline 4 & $30: 50: 30.7$ & 78:36:57.91 & 2015 & $\begin{array}{c}16 \text { March } 2006 \& \text { } \\
\text { 2:16 p.m. }\end{array}$ & $\begin{array}{c}19 \text { March } 2006 \& \text { } \\
\text { 12:30 p.m. }\end{array}$ \\
\hline 5 & $30: 46: 22.27$ & $78: 36: 9.22$ & 1404 & $\begin{array}{c}18 \text { March } 2006 \& \\
1: 25 \text { p.m. }\end{array}$ & $\begin{array}{c}20 \text { March } 2006 \& \\
\text { 4:00 p.m. }\end{array}$ \\
\hline 6 & 30:54:10.84 & $78: 40: 55.20$ & 2038 & $\begin{array}{c}13 \text { May } 2006 \& \\
\text { 3:07 p.m. }\end{array}$ & $\begin{array}{c}16 \text { May } 2006 \& \text { } \\
10.00 \text { a.m. }\end{array}$ \\
\hline 7 & $31: 02: 22.42$ & 78:47:56.37 & 2591 & $\begin{array}{l}17 \text { May } 2006 \& \text { } \\
\text { 8:15 p.m. }\end{array}$ & $\begin{array}{c}20 \text { May } 2006 \& \\
11.00 \text { a.m. }\end{array}$ \\
\hline 8 & $31: 02: 14.82$ & $78: 51: 21.31$ & 2747 & $\begin{array}{c}20 \text { May } 2006 \& \text { } \\
\text { 3:18 p.m. }\end{array}$ & $\begin{array}{c}23 \text { May } 2006 \& \text { } \\
10.00 \text { a.m. }\end{array}$ \\
\hline
\end{tabular}

The output voltage of an induction coil is proportional to the number of loops in the coil and their cross-sectional area. The response of the induction coil is governed by the rate of change of magnetic flux within the coil (Kaufmann and Keller, 1981). The voltage response recorded by the induction coil is transformed into the magnetic field units using transfer function of the coil. A separate coil was deployed for each horizontal component with a separation of 6-8 m between them in order to avoid any cross-talk.

The ADU06 is the central core unit of the Metronix MT system. It contains the complete circuitry for analog signal conditioning, the $24 \mathrm{Bit} \mathrm{A} / \mathrm{D}$ converter, the data storage as well as a very precise GPS controlled time base.

The magnetotelluric data are recorded in the 5 bands: HF, LF1, Free, LF2 and LF3, each band is characterized by a different sampling rate. All these bands together constitute a complete time series data to cover a frequency range from 0.001 to $1000 \mathrm{~Hz}$. However, in the Schumann resonance study, we require the data for the frequency interval of 1 to $30 \mathrm{~Hz}$, to cover the first three resonance mode frequencies, which were obtained from the time series data recorded in the LF2 band, with a sampling frequency of $64 \mathrm{~Hz}$. Time series data in the LF2 band was recorded continuously for $24 \mathrm{~h}$ or more. According to the sampling theory, Fourier transformation of 2048 sample points recorded at $64 \mathrm{~Hz}$ sampling frequency (LF2 band), generates a frequency spectrum between $0.03-32 \mathrm{~Hz}$ with a frequency resolution of $0.03 \mathrm{~Hz}$. Thus, the frequency band obtained, includes the first three Schumann resonance modes. Figure 1 shows an example of the hourly frequency spectrum of two magnetic field components recorded in the form of time series, in LF2 band, from the Garhwal Himalayan region at Dharali (lat. 31:02:22.42; long. 78:47:56.37) on 18 May 2006. Figure 1 shows that generally the first three resonance frequencies are successfully recovered from the data.

\section{Spectral analysis of MT data}

The time domain record of the electromagnetic field describes the temporal response of earth-ionospheric cavity. The data are transformed into the frequency domain using FFT algorithms by using 2048 points (32 s) in each window length. Individual power spectra, obtained from a segment of 2048 sample points, are averaged over $\mathrm{N}$ segments to improve the signal to noise ratio. This stabilization of the power spectrum for varying $\mathrm{N}$ is displayed in Fig. 2. The horizontal axis shows the frequency and vertical axis is shifted vertically for each $\mathrm{N}$ value, to represent power spectra in arbitrary scale. Schumann resonance modes are not clearly visible by using only one segment $(\mathrm{N}=1)$. When the number $\mathrm{N}$ of segments increases, the SR modes become visible. The spectrum is stabilized and the first three SR modes frequencies are clearly visible in the power spectra of the magnetic field $\left(H_{x}\right)$ component for $\mathrm{N}=32$ (Fig. 2). The objective was to find out the minimum value of $\mathrm{N}$, for the visibility of SR modes frequencies. Figure 3 shows the amplitude spectral variation with frequency during the night, sunrise, noon and solar-terminator (sunset) in horizontal electric and magnetic field components. It is clear, from Fig. 3, that the amplitude spectral variation shows its maximum value during the noon and its minimum value during the night. The analysis was done for one hour LT data: night (00:00-01:00 h), sunrise 

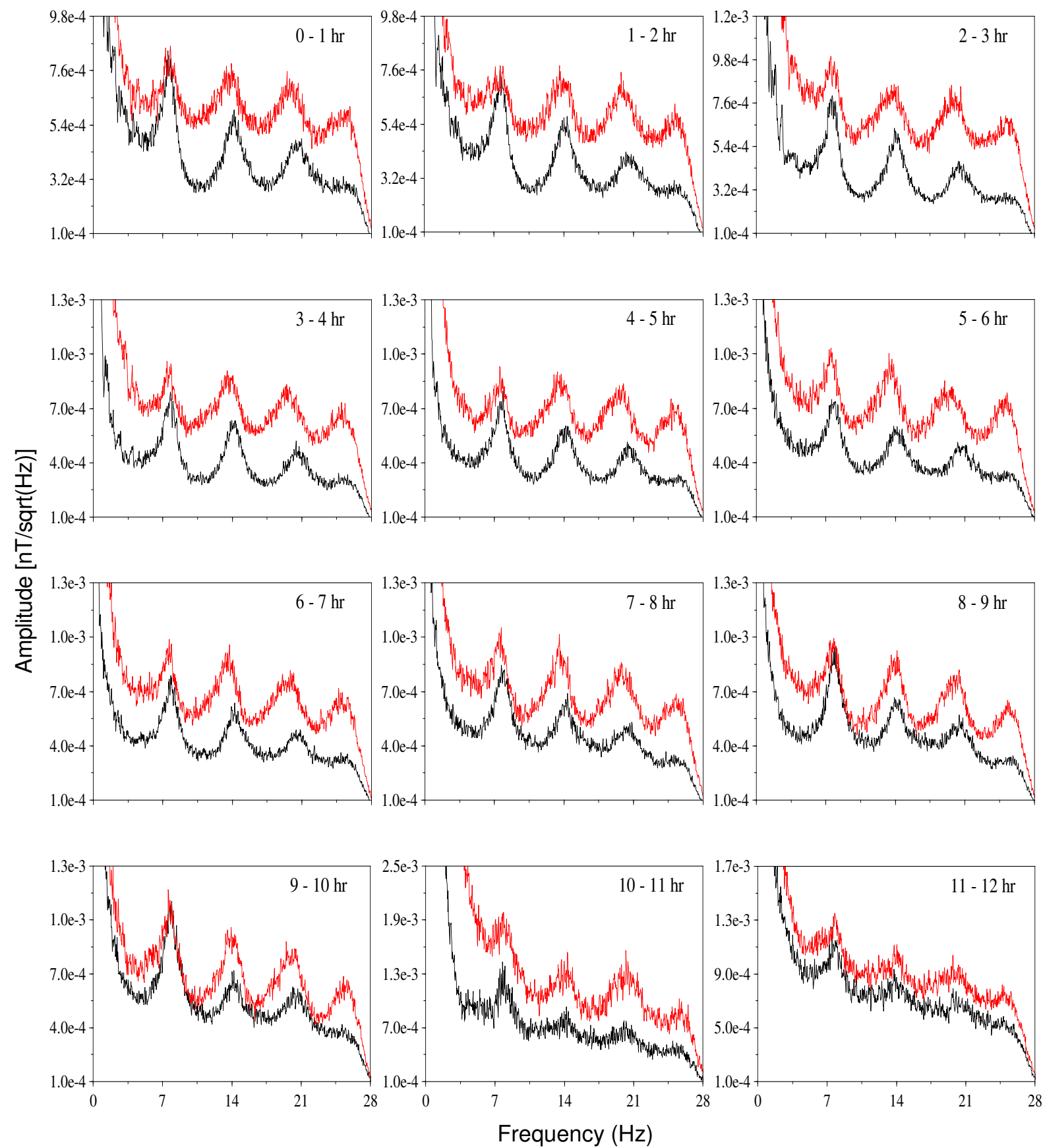

Fig. 1. The hourly variation in amplitude-frequency spectrum of two magnetic field components $\left(H_{x}\right.$ and $\left.H_{y}\right)$, from the Garhwal Himalayan region recorded at Dharali (lat. 31:02:22.42; long. 78:47:56.37) on 18 May 2006. $H_{x}$ and $H_{y}$ components are shown in black and red, respectively.

(06:00-07:00 h), noon (13:00-14:00 h) and sunset (18:0019:00 h) and the frequency spectrum was obtained for each of the above time intervals. It has been observed that the frequency and amplitude variations are different in N-S and E-W electric and magnetic field components. Generally, diurnal variations of SR frequencies, for the first three modes in electric and magnetic field components, indicate that the pair of field components belonging to the same polarization (e.g. $E_{x} \& H_{y}$, or $E_{y} \& H_{x}$ ) have similar frequency variation. It means that the information content in the two field components $\left(E_{x} \& H_{y}\right.$, or $\left.E_{y} \& H_{x}\right)$ corresponding to the same polarization are the same. However, frequency variation in the two field components, belonging to the different polarization, show opposite phase, which means that the 

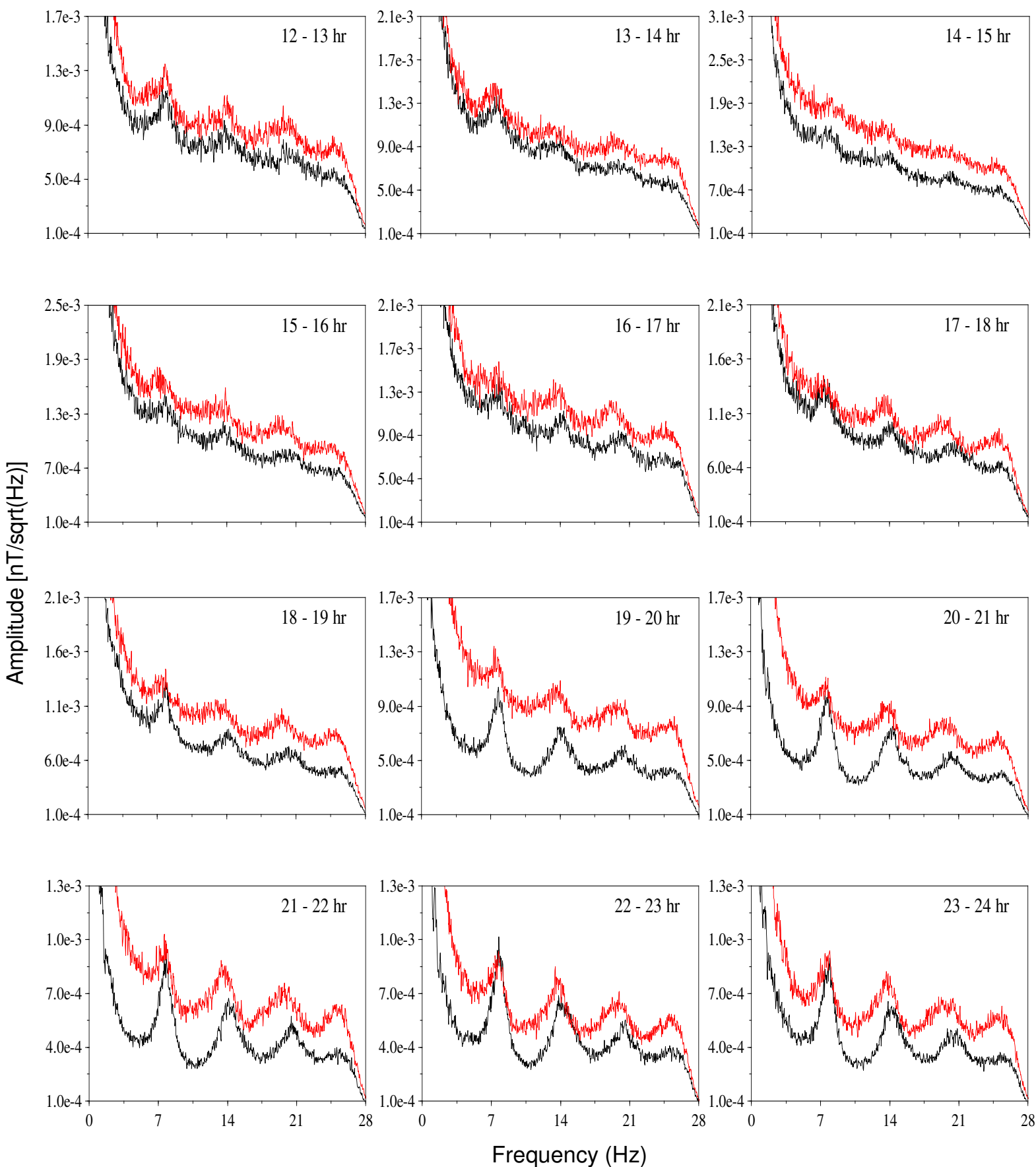

Fig. 1. Continued.

frequency variations are opposite in the two field components. Figure 4 demonstrates diurnal variation in SR frequencies for mode 3 for the different polarization components $\left(E_{x}, E_{y}\right.$ and $\left.H_{x}, H_{y}\right)$. It is observed that during sunrise the $E_{x}$ component shows a decrease in frequency, whereas in $H_{x}$ the frequency is increased (Fig. 4), hence the frequency variation in $E_{x} \& H_{x}$ components are opposite in phase. This feature is generally observed in the entire set of data that has been analyzed. To improve the statistics, average diurnal frequency variation in the first three SR modes, in the data recorded from 10 March-23 May 2006, in electric and magnetic field components along with standard deviation is shown in Fig. 5. Generally, periodic frequency variations are observed in all field components. For example $H_{x}$ component shows maximum frequency during LT sunrise $(06: 00 \mathrm{~h})$ and sunset $(18: 00 \mathrm{~h})$ in first mode, similarly, 


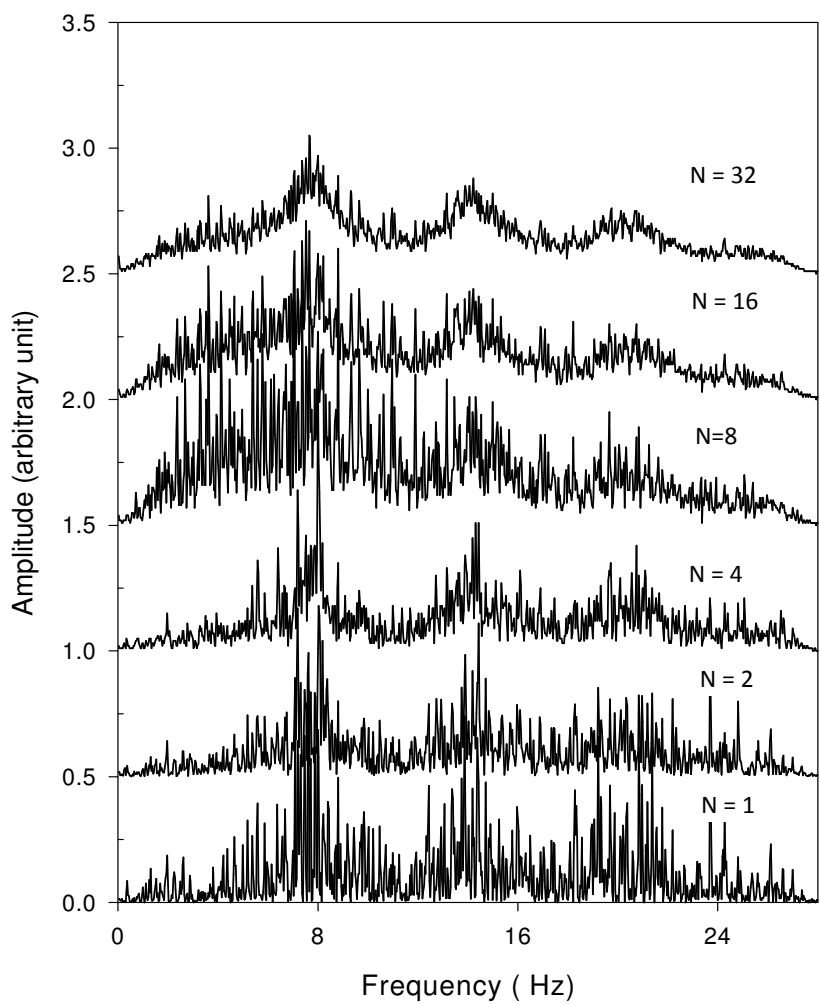

Fig. 2. Natural stabilization of stacked spectral estimates at first three Schumann Resonance (SR) modes for magnetic field $\left(H_{x}\right)$ component in the Garhwal Himalayan region. The horizontal axis represents the frequency and vertical axis, the amplitude, in shifted arbitrary scale for a different number of stacked segment $(\mathrm{N})$.

$H_{y}$ component shows minimum frequency during LT sunrise and sunset (Fig. 5). It may also be mentioned here that in some components, the periodicity is not so clearly visible. The frequency variation in different components varies from 1.9 to $4.2 \%, 1.5$ to $3.1 \%$ and 1.8 to $3.4 \%$ in first, second and third SR modes.

\section{Estimation of electron density in lower ionosphere}

Electromagnetic resonance frequencies, mainly excited by lightning discharge in the cavity formed by the earth and the ionosphere, were estimated by Schumann (1952) using the simplest vacuum model confined within two concentric perfectly conducting spheres. Subsequently, it was investigated that SR frequency depends on the dielectric permeability of ionospheric D-region and the focus was shifted to use more realistic dielectric permeability models to explain the observed SR frequencies (Balser and Wagner, 1962; Bliokh et al., 1980). Greifinger and Greifinger (1978); Sentman (1983, 1990) considered the ionospheric model, in which dielectric permeability increases exponentially with altitude, which has generated resonance frequencies, in good agreement with the observations. Sentman and Fraser (1991) showed the dependence of the observed resonance power on the effective height of the ionospheric D-region at the observation point. Ionospheric dielectric permeability is mainly determined by the electron density and the collision frequency between neutral particles and electrons within the lower ionosphere (Dlayer). The electron density changes regularly with the position of the sun, during geomagnetic storm and solar flares etc. Any change in the electrons density in lower ionosphere modifies its dielectric permeability, which plays an important role in modifying the SR frequency.

Roldugin et al. (1999) showed that the SR frequency depends both on the electron density in the ionospheric Dregion and on the base height of this region. For the interpretation of our data, we now consider, in some detail, the simple model of Roldugin et al. (2003), for which the authors establish a quantitative relation between SR frequencies and the ionospheric parameters. Considered is a two-layer model, where the discontinuous relative electrical permittivity assumes the values [taking $z$ from the Earth's surface positive upwards and assuming a time factor $\exp (i \omega t)]$

$\varepsilon(z)=\left\{\begin{array}{l}1,0 \leq z<a, \\ \frac{\omega_{02}^{2}}{i \omega v_{e 2}} \exp [(z-a) / h]=\frac{\sigma_{2}}{i \omega \varepsilon_{0}} \exp [(z-a) / h], z>a .\end{array}\right.$

The first layer is the non-conducting air layer and the second layer models the D-region with its base at $z=a$. It is characterized either by the plasma frequency $\left(\omega_{02}\right)$ and electron collision frequency $v_{e 2}$ at $z=a$ or by the electrical conductivity $\left(\sigma_{2}\right)$ at that level. These parameters can be defined as (Nickolaenko and Hayakawa, 2002; Bliokh et al., 1980)

$\omega_{02}^{2}=\frac{N_{2} e^{2}}{m_{e} \varepsilon_{0}}, \quad \sigma_{2}=\frac{N_{2} e^{2}}{m_{e} v_{e 2}}=\frac{\omega_{02}^{2} \varepsilon_{0}}{v_{e 2}}$,

where $N_{2}$ is the electron density at $z=a, e$ the electric unit charge, $m_{e}$ the electron mass and $\varepsilon_{0}$ the vacuum permittivity. The model in Eq. (2), assumes that in the D-layer the ratio $N_{e}(z) / v_{e}(z)$ or equivalently the electrical conductivity $\sigma(z)$ increases exponentially with the scale height $h$. The ionospheric model defined by Eq. (2), is a low-frequency approximation based on the valid relations $\omega \ll v_{e 2}$ and $\omega \ll \omega_{02}^{2} / \nu_{e 2}$. The latter condition means that at the base of the ionosphere, the conduction current is greater than the displacement current.

From this model of the lower ionosphere, Roldugin et al. (2003) determine the SR frequencies in terms of the ionospheric parameters. We believe, however, that their corresponding formula is incorrect and propose the following slightly modified alternative for the SR frequency,

$$
\omega=\frac{c \sqrt{n(n+1)}}{R_{E}} \cdot \frac{1}{\sqrt{1-\frac{2 h}{a}\left[\gamma+\ln \left(\frac{\omega_{02} h}{c} \sqrt{\frac{i \omega}{v_{e 2}}}\right)\right]}},
$$

$n=1,2, \ldots$, where $\gamma=0.577$ is Euler's constant. Our formula given by Eq. (4), differs from the corresponding formula of Roldugin et al. (2003) in two important details: 

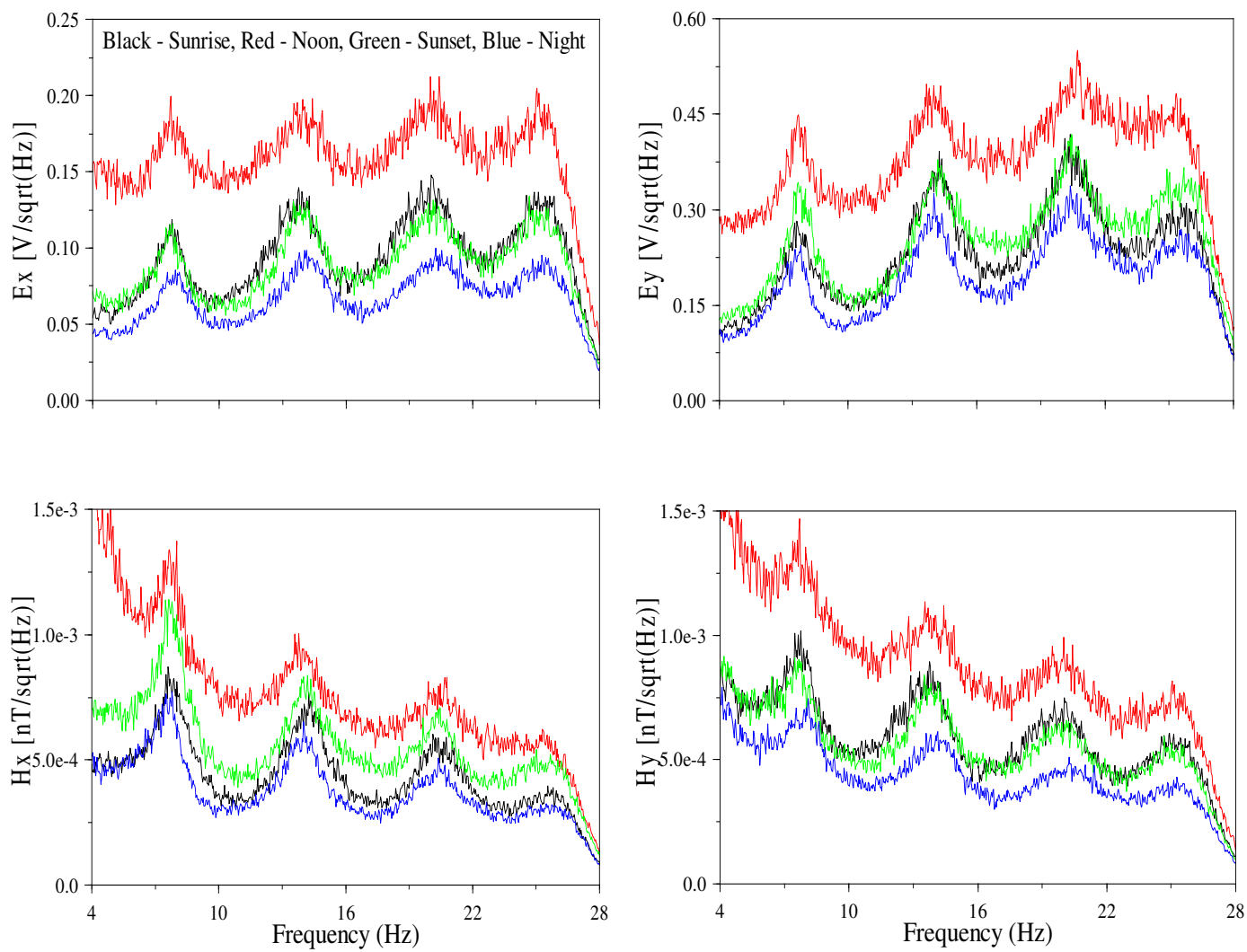

Fig. 3. Amplitude spectral variation in the frequency during the night, sunrise, noon and sunset time for electric and magnetic field components recorded on 21 May 2006 at Lanka site (lat. 31:02:14.82; long. 78:51:21.31). [Black: sunrise, Red: noon, Green: sunset, Blue: night].
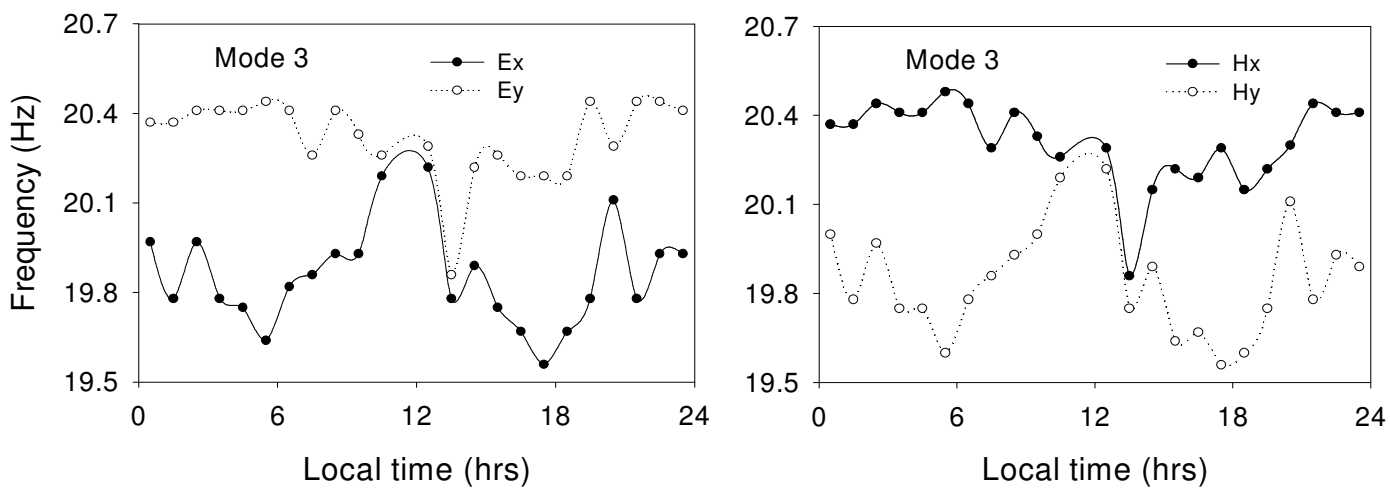

Fig. 4. The diurnal variations of the third Schumann resonance mode frequency, showing the frequency variation is not in the same phase for different components. However, different components in the same polarization show a similar behaviour.

a) The sign in front of $\gamma$ has been changed from - to + . With this correction, the electron density $N_{2}$ as estimated from $R_{E}(\omega)$ (with $a, h$ and $v_{e 2}$ given), is reduced by a factor of $\exp (4 \gamma) \approx 10$.

b) Also the sign in front of the imaginary unit $i$ has been changed from - to + . This change is required when considering the more complete small argument expansion of the Hankel function as,
$H_{0}^{(2)}(\chi)=1-\frac{2 i}{\pi}[\gamma+\ln (\chi / 2)]+O\left(\chi^{2}\right)$,

with $\chi=2 k h \sqrt{\varepsilon_{2}}$, where the first term is missing in Eq. (21) of Roldugin et al. (2003). The correction changes the sign of the imaginary part of $\omega$ and renders $\operatorname{Im}(\omega)$ positive. This positivity is required in order that the time factor $\exp (i \omega t)$ describes a decaying dissipative signal. On the other hand, the negative imaginary parts of the SR resonances, produced 

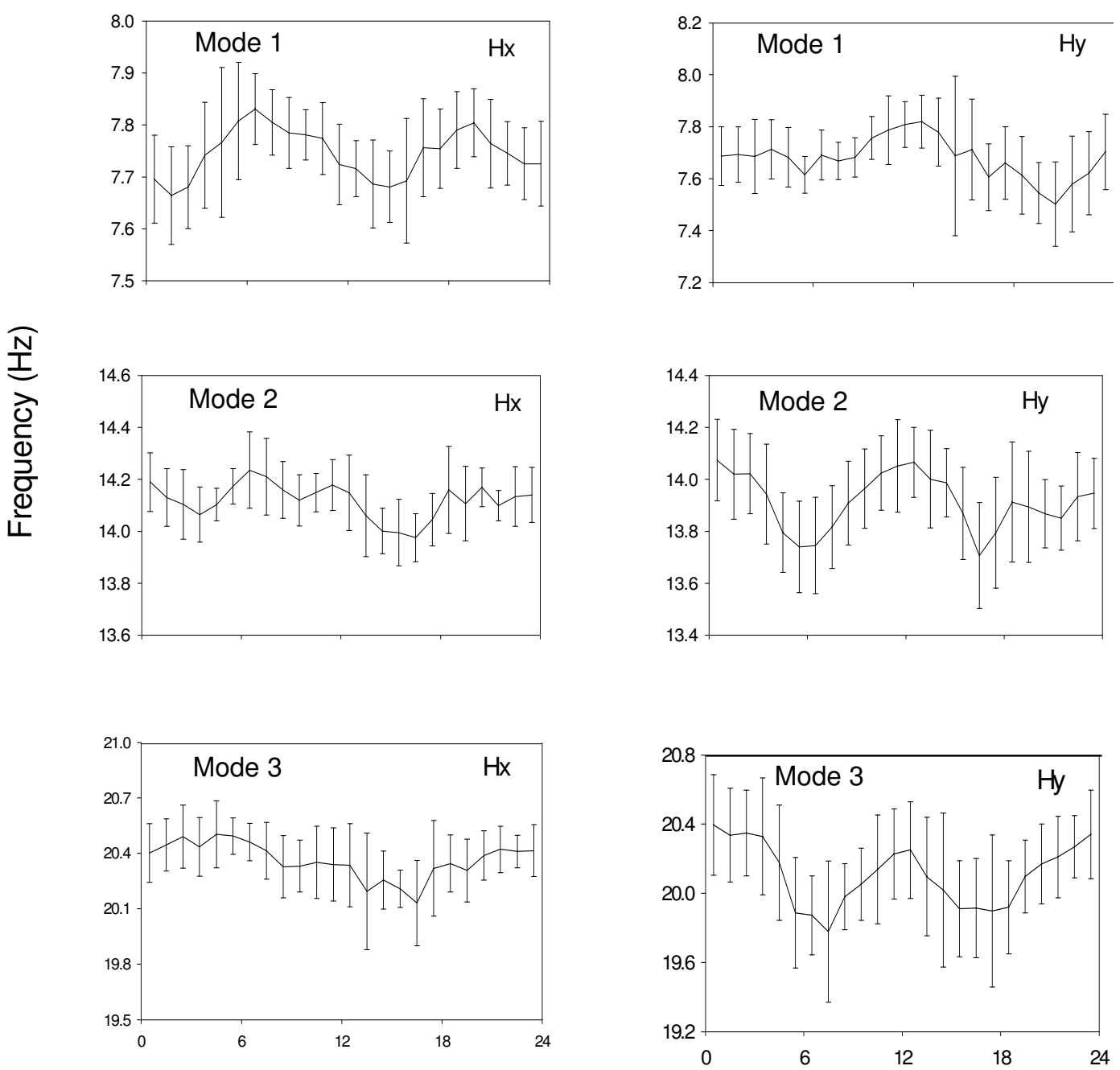

\section{Local time (hrs)}

Fig. 5. The average diurnal frequency variation observed in the first three SR modes frequency of magnetic field components during, 10 March-23 May 2006. Error bar indicates standard deviation.

by the Roldugin et al. (2003), are incompatible with this time factor.

After inserting reasonable ionospheric parameters into Eq. (4), we also arrive at a reasonable set of SR frequencies. Assuming for example

$a=55 \mathrm{~km}, h=7 \mathrm{~km}, N_{2}=4 \times 10^{7} \mathrm{~m}^{-3}, v_{e 2}=10^{7} \mathrm{~s}^{-1}$,

the first three SR resonances are:

$f_{1}=(7.71+0.43 i) \mathrm{Hz}, f_{2}=(13.62+0.78 i) \mathrm{Hz}$,

$f_{3}=(19.51+1.15 i) \mathrm{Hz}$.

Since $\omega$ occurs also on the right-hand side of Eq. (4), a few iterations are required to get the final values. Apart from the sign, the imaginary parts of the SR frequencies Eq. (6) are about a factor two greater than those predicted by Roldugin et al. (2003), Eqs. (25) and (27), and are, thus, closer to the experimentally determined values displayed in their Fig. 5.

Equation (4) is now used to determine the daily variation of electron density $N_{2}$ from the experimental values of $\operatorname{Re}\left(f_{n}\right)$, given $a, h$ and $v_{e 2}$. From Eqs. (2) and (3) or Eqs. (4) and (3) it is inferred that only the ratio $N_{2} / v_{e 2}$ can be resolved. With the parameters $a=61.00 \mathrm{~km}, h=$ variable, $v_{e 2}=10^{7} \mathrm{~s}^{-1}$, the estimated electron density $N_{2}$ is obtained from Eq. (4) after solving a simple nonlinear equation. For $n=2$ the results are displayed in Fig. 6, for four values (5.0, $6.0,6.5$ and $7.0 \mathrm{~km}$ ) of scale height $(h)$, where they are compared with the values derived from the IRI model. It has been observed that for $h=6.5 \mathrm{~km}$, electron density $N_{2}$ matches closely with the values derived from IRI model. The method discussed by Ishisaka et al. (2005), to determine electron 

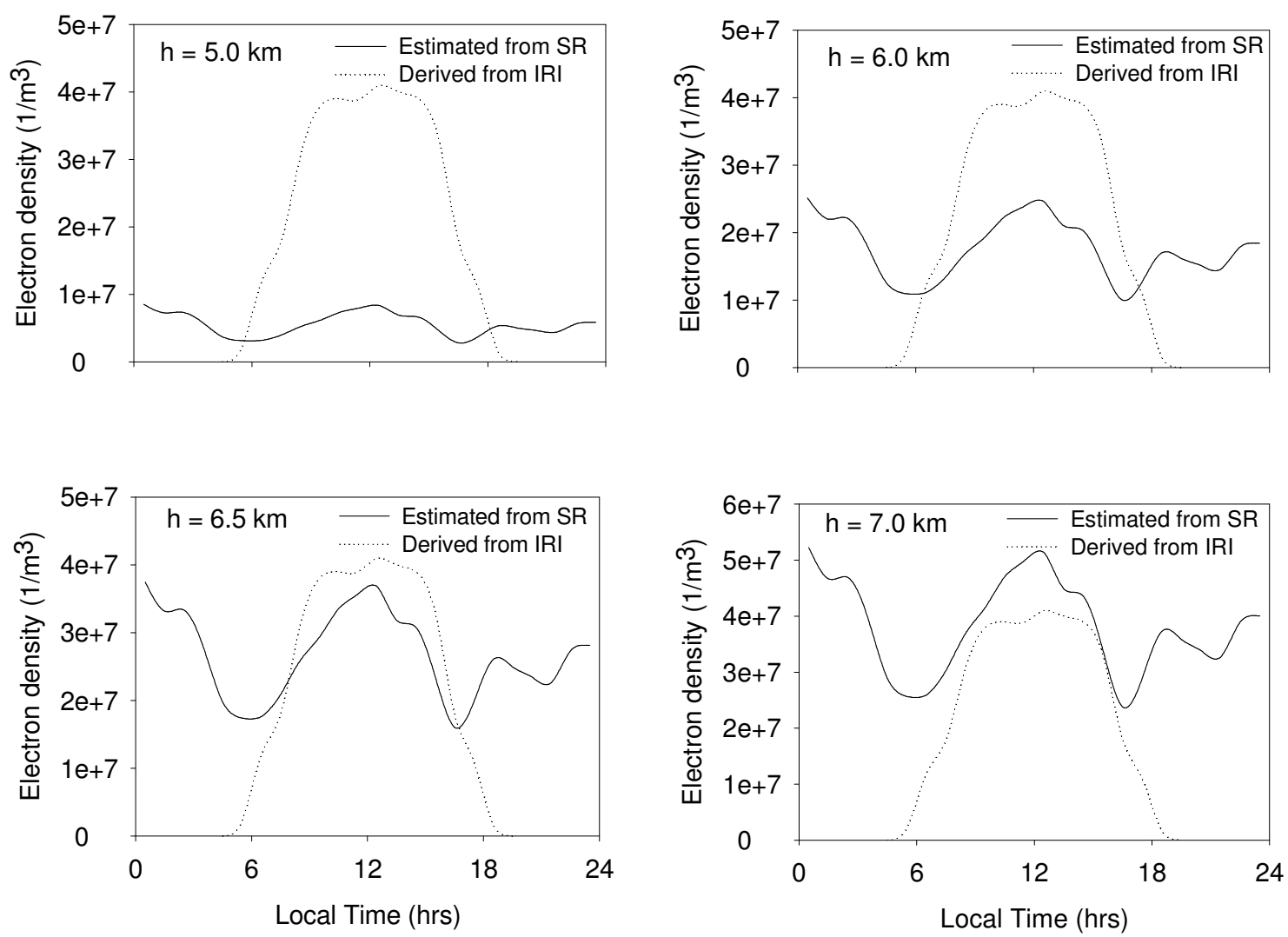

Fig. 6. Electron density estimated from second mode $(n=2)$ Schumann resonance frequency for varying scale height $(h)$ along with values derived from IRI model in lower ionospheric layer (D-layer).

density in lower ionosphere, has been used to obtain electron density from IRI model in lower ionosphere. It may also be mentioned, that the IRI values are shown only in day time as the IRI model in not applicable in nighttime for lower ionosphere.

Finally, Fig. 7 shows a corresponding display of the observed and calculated quality factor, $Q=\operatorname{Re}\left(f_{n}\right) /\left[2 \operatorname{Im}\left(f_{n}\right)\right]$, which gives the number of periods, after which the energy is decreased by a factor of $1 / \mathrm{e}=0.37$. Observed quality factor is obtained from the data presented in Fig. 1. The imaginary part $\left[\operatorname{Im}\left(f_{n}\right)\right]$ is the half width of spectral peak.

\section{Conclusions}

In the present study, the spectral analysis of magnetotelluric data recorded from the Garhwal Himalayan region, India, has been conducted to study the Schumann resonance frequency variation. Orthogonal horizontal (N-S and E-W) time varying electric and magnetic field components data recorded in the Himalayan region, at 8 stations during 10 March-23 May 2006, have been used for this purpose. Fast Fourier Transform (FFT) algorithm has been used to obtain a frequency spectrum with a resolution of $0.03 \mathrm{~Hz}$. Same polarization

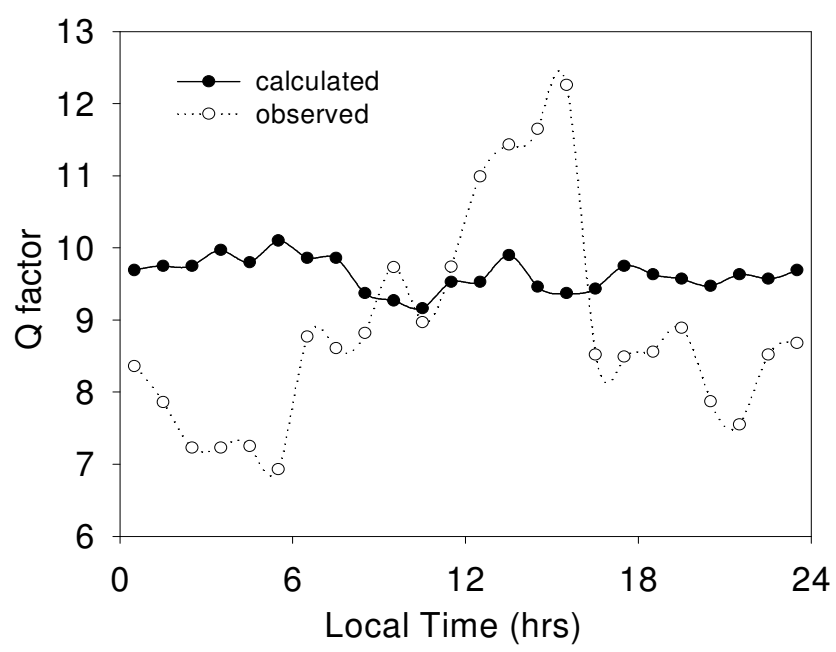

Fig. 7. Comparison of observed and calculated (Eq. 4) quality factor $(\mathrm{Q})$ for second mode $(n=2)$ Schumann resonance frequency. Observed quality factor is obtained from the recorded data as $\mathbf{Q}=\operatorname{Re}\left(f_{n}\right) /\left[2 . \operatorname{Im}\left(f_{n}\right)\right]$, the $\operatorname{Im}\left(f_{n}\right)$ is the half width of the spectral peak. 
components, show a similar variation in SR frequencies. Different frequency variations have been obtained for the northsouth (N-S) and east-west (E-W) magnetic field components in the SR mode frequencies. Spectral analysis shows an average periodic variation in SR frequencies, however, the variation in the two magnetic field components are not in the same phase. The frequency variation is related to the effective size of the thunderstorm and associated ionospheric conductivity. The frequency variation in different components varies from 1.9 to $4.2 \%, 1.5$ to $3.1 \%$ and 1.8 to $3.4 \%$ in the first, second and third SR modes.

Finally, electron density variation and the corresponding attenuation factor in lower ionosphere are estimated from SR frequency, observed in the Indian region, assuming a constant lightning source distribution.

Acknowledgements. The authors wish to express their sincere thanks to Sri Niwas, P. K. Gupta and D. K. Tyagi for their valuable support during the course of work. The Data acquisition was carried out with the financial support from Department of Science and Technology, Govt. of India. The authors are thankful to the reviewers for their constructive suggestion to improve the quality of the paper. Specially, the encouragement and positive direction shown by the second reviewer has been extremely useful to bring the scientific content of the paper in its present form, we are thankful for his encouragement and suggestions. The authors are thankful to Nagendra Kumar for sparing his valuable time for reading the final manuscript. One of the authors (Ramesh Chand) is thankful to the Council of Scientific and Industrial Research (CSIR), New Delhi, for providing the financial assistance.

Topical Editor C. Jacobi thanks two anonymous referees for their help in evaluating this paper.

\section{References}

Balser, M. and Wagner, C. A.: Diurnal power variations of the Earth-ionosphere cavity modes and their relationship to worldwide thunderstorm activity, J. Geophys. Res., 67, 619-625, 1962.

Beamish, D. and Tzanis, A.: High resolution spectral characteristics of the Earth-ionosphere cavity resonances, J. Atmos. Terr. Phys., 48, 187-203, 1986.

Bliokh, P. V., Nikolaenko, A. P., and Filippov, Y. F.: Schumann resonances in the Earth-ionosphere cavity, Peter Peregrinus, London 9, 168, 1980.

Füllekrug, M.: Schumann resonances in magnetic field components, J. Atmos. Terr. Phys., 57, 479-484, 1995.

Greifinger, C. and Greifinger, P.: Approximate method for determining ELF eigenvalues in the earth-ionosphere waveguide, Radio Sci., 13, 831-837, 1978.

Grimalsky, V., Koshevaya, S., Kotsarenko, A., and Perez Enriquez, R.: Penetration of the electric and magnetic field components of Schumann resonances into the ionosphere, Ann. Geophys., 23, 2559-2564, 2005, http://www.ann-geophys.net/23/2559/2005/.

Hayakawa, M., Nickolaenko, A. P., Sekiguchi, M., Yamashita, K., Ida, Y., and Yano, M.: Anomalous ELF phenomena in the Schumann resonance band as observed at Moshiri (Japan) in possible association with an earthquake in Taiwan, Nat. Hazards Earth
Syst. Sci., 8, 1309-1316, 2008,

http://www.nat-hazards-earth-syst-sci.net/8/1309/2008/.

Ishisaka, K., Okada, T., Hawkins, J., Murakami, S., Miyake, T., Murayama, Y., Nagano, I., and Matsumoto, H.: Investigation of electron density profile in the lower ionosphere by SRP-4 rocket experiment, Earth Planets Space, 57, 879-884, 2005.

Israil, M., Tyagi, D. K., Gupta, P. K., and Niwas, S.: Magnetotelluric investigations for imaging electrical structure of Garhwal Himalayan corridor, Uttarakhand, India, J. Earth Syst. Sci., 117, 189-200, 2008.

Kaufmann, A. A. and Keller, G. V.: The magnetotelluric sounding method, Elsevier Scientific Publishing Company, Amsterdam, 1981.

Madden, T. and Thompson, W.: Low frequency electromagnetic oscillations of the Earth-ionosphere cavity, Rev. Geophys., 3, $211-$ 254, 1965.

Märcz, F., Sátori, G., and Zieger, B.: Variations in Schumann resonances and their relation to atmospheric electric parameters at Nagycenk station, Ann. Geophys., 15, 1604-1614, 1997 , http://www.ann-geophys.net/15/1604/1997/.

Melnikov, A., Price, C., Sátori, G., and Füllekrug, M.: Influence of solar terminator passages on Schumann resonance parameters, J. Atmos. Solar-Terr. Phys., 66, 1187-1194, 2004.

Nickolaenko, A. P.: Modern aspects of Schumann resonance studies, J. Atmos. Solar-Terr. Phys., 59, 805-816, 1997.

Nickolaenko, A. P. and Hayakawa, M.: Resonances in EarthIonosphere cavity, Kluwer, Dordrecht, 392, 2002.

Pierce, E. T.: Excitation of Erath-ionosphere resonances by lightning flashes, J. Geophys. Res., 68, 4125-4127, 1963.

Roldugin, V. C., Maltsev, Ye. P., Vasiljev, A. N., and Vashenyuk, E. V.: Changes of the first Schumann resonance frequency during relativistic solar proton precipitation in the 6 November 1997 event, Ann. Geophys., 17, 1293-1297, 1999,

http://www.ann-geophys.net/17/1293/1999/.

Roldugin, V. C., Maltsev, Y. P., Petrova G. A., and Vasiljev, A. N.: Decrease of the first Schumann resonance frequency during solar proton events, J. Geophys. Res., 106, 18555-18562, 2001.

Roldugin, V. C., Maltsev, Y. P., Vasiljev, A. N., Shvets, A. V., and Nikolaenko, A. P.: Changes of Schumann resonance parameters during the solar proton event of 14 July, 2000, J. Geophys. Res., 108, 1103, doi:10.1029/2002JA009495, 2003.

Roldugin, V. C., Maltsev, Y. P., Vasiljev, A. N., Schokotov, A. Y., and Belyajev, G. G.: Diurnal variations of Schumann resonance frequency in NS and EW magnetic components, J. Geophys. Res., 109, A08304, doi:10.1029/2004JA010487, 2004a.

Roldugin, V. C., Maltsev, Y. P., Vasiljev, A. N., Schokotov, A. Y., and Belyajev, G. G.: Schumann resonance frequency increase during solar X-ray bursts, J. Geophys. Res., 109, A01216, doi:10.1029/2003JA010019, 2004b.

Sao, K., Yamashita, M., Tanahashi, S., Jindoh, H., and Ohta, K.: Experimental investigations of Schumann resonance frequencies, J. Atmos. Terr. Phys., 35, 2047-2053, 1973.

Sátori, G.: Monitoring Schumann resonances - II. Daily and seasonal frequency variations, J. Atmos. Terr. Phys., 58, 1483-1488, 1996.

Sátori, G., Williams, E., and Mushtak, V.: Response of the Earthionosphere cavity resonator to the 11-year solar cycle in Xradiation, J. Atmos. Solar-Terr. Phys., 67, 553-562, 2005.

Schumann, W. O.: Über die strahlungslosen Eigenschwingun- 
gen einer leitenden Kugel, die von einer Luftschicht und einer Ionosphärenhülle umgeben ist, Z. Naturforsch., 7a, 149-154, 1952.

Sentman, D. D.: Schumann resonance effects of electrical conductivity perturbations in an exponential atmospheric/ionospheric profile, J. Atmos. Terr. Phys., 45, 55-66, 1983.

Sentman, D. D.: Magnetic elliptical polarization of Schumann resonances, Radio Sci., 22, 595-606, 1987.

Sentman, D. D.: Detection of elliptical polarization and mode splitting in discrete Schumann resonance excitations, J. Atmos. Terr. Phys., 51, 507-519, 1989.

Sentman, D. D.: Approximate Schumann resonance parameters for a two-scale height ionosphere, J. Atmos. Terr. Phys., 52, 35-46, 1990.

Sentman, D. D. and Fraser, B. J.: Simultaneous observations of Schumann resonances in California and Australia: evidence for intensity modulation by the local height of the D region, J. Geophys. Res., 96, 15973-15984, 1991.
Sentman, D. D.: Schumann resonance spectra in a two-scaleheight Earth-ionosphere cavity, J. Geophys. Res., 101, 94799487, 1996.

Tran, A. and Polk, C.: Schumann resonances and electrical conductivity of the atmosphere and lower ionosphere-I. Effects of conductivity at various altitudes on resonance frequencies and attenuation, J. Atmos. Terr. Phys., 41, 1241-1248, 1979a.

Tran, A. and Polk, C.: Schumann resonances and electrical conductivity of the atmosphere and lower ionosphere-II. Evaluation of the conductivity profiles from experimental Schumann resonance data, J. Atmos. Terr. Phys., 41, 1249-1261, 1979 b.

Tulunay, Y., Altuntas, E., Tulunay, E., Price, C., Ciloglu, T., Bahadirlar, Y., and Senalp, E. T.: A case study on the ELF characterization of the Earth-ionosphere cavity: Forecasting the Schumann resonances intensities, J. Atmos. Solar-Terr. Phys., 70, 669-674, 2008. 